\title{
AETIOLOGICAL PROFILE OF NEONATAL HYPERBILIRUBINEMIA IN NEONATAL INTENSIVE CARE UNIT OF GAUHATI MEDICAL COLLEGE AND HOSPITAL, GUWAHATI, ASSAM
}

\author{
Dulal Kalita1, Gyanam Mishra², Vivekananda Matada Shivananda ${ }^{3}$ \\ ${ }^{1}$ Assistant Professor, Department of Paediatrics, Gauhati Medical College and Hospital, Guwahati, Assam. \\ ${ }^{2}$ Registrar, Department of Paediatrics, Gauhati Medical College and Hospital, Guwahati, Assam. \\ ${ }^{3}$ Post Graduate Trainee, Department of Paediatrics, Gauhati Medical College and Hospital, Guwahati, Assam.
}

\begin{abstract}
\section{BACKGROUND}

Jaundice is the most common problem in the first week of life. About $25-50 \%$ of all term neonates and higher percentage of preterm neonates develop clinical jaundice during neonatal period. Jaundice in newborn is a medical emergency, because unconjugated hyperbilirubinemia may cause bilirubin encephalopathy and needs urgent treatment. The objective of the study was to know the aetiology of hyperbilirubinemia in neonate admitted in neonatal intensive care unit of Gauhati Medical College and Hospital.
\end{abstract}

\section{METHODS}

This observational study was conducted in Neonatal Intensive Care Unit, Gauhati Medical College and Hospital, over a period of one year (February 2015 to January 2016). A total number of 520 neonates with hyperbilirubinemia were included in the present study. Data collection was done by history taking, clinical examination and essential laboratory tests.

\section{RESULTS}

In this study, out of 520 jaundiced neonates 251 (48.26\%) were term babies and 269 (51.74\%) were preterm babies. Physiological jaundice was seen in 224 (43.07\%) babies and pathological jaundice were 296 (56.93\%) babies. Among the various aetiologies causing neonatal hyperbilirubinemia, the most common causes were physiological jaundice 224 (43.07\%), ABO incompatibility 108 (20.76\%), Idiopathic 54 (10.43\%), neonatal sepsis 36 (6.92\%), G6PD deficiency 35 (6.73\%) and Rh Incompatibility 31 (5.96\%). Other less common causes were cephalhematoma 15 (2.88\%), intrauterine infection 7 (1.34\%), breast milk jaundice $6(1.15 \%)$ and hypothyroidism 4 (0.76\%).

\section{CONCLUSION}

We should investigate all newborns with pathological jaundice to find out the aetiology. Moreover, early detection of neonatal jaundice, proper monitoring and timely interventions like phototherapy, exchange blood transfusion and treating the underlying cause will reduce the morbidity and mortality among neonates. Thus, we can prevent mental retardation and cerebral palsy due to neonatal hyperbilirubinemia at the community level.

\section{KEYWORDS}

Neonate, Hyperbilirubinemia, Physiological Jaundice, Pathological Jaundice, ABO incompatibility, Rh Incompatibility, G6PD deficiency, Kernicterus.

HOW TO CITE THIS ARTICLE: Kalita D, Mishra G, Shivananda VM. Aetiological profile of neonatal hyperbilirubinemia in neonatal intensive care unit of Gauhati Medical College and Hospital, Guwahati, Assam. J. Evolution Med. Dent. Sci. 2016;5(34):1865-1868, DOI: $10.14260 /$ jemds/2016/440

\section{INTRODUCTION}

Jaundice is the most common problem in the first week of life. About $25-50 \%$ of all term neonates and higher percentage of preterm babies develop clinical jaundice during neonatal period. It is the commonest cause of admission to NICU in the neonatal period. Clinically, it is observed when the serum bilirubin exceeds $5 \mathrm{mg} / \mathrm{dL}$ in neonates and $>2 \mathrm{mg} / \mathrm{dL}$ in adults.(1) The peculiarities of neonatal jaundice is its cephalopedal progression due to relative thickness of the skin at various part, thinnest over the face and thickest over the palm and soles.

Financial or Other, Competing Interest: None.

Submission 28-02-2016, Peer Review 09-03-2016,

Acceptance 14-03-2016, Published 26-04-2016.

Corresponding Author:

Dr. Dulal Kalita,

House No. 24,

Adarashapur, Byelane 4,

Kahilipara-781019,

Guwahati, Assam.

E-mail: dulalkalita68@gmail.com

DOI: $10.14260 /$ jemds $/ 2016 / 440$
Hence, yellowish discolouration is first seen over the skin of the face, nasolabial fold, tip of the nose and at last at soles and palms. Extent of jaundice thus detected gives a rough estimate of serum bilirubin (Krammer et al, 1969).(2), Krammer's criteria to estimate clinical jaundice as follows: face $4-8 \mathrm{mg} / \mathrm{dL}$, upper trunk $5-12 \mathrm{mg} / \mathrm{dL}$, lower trunk and thighs 8-16 mg/dL, arms and lower legs $11-18 \mathrm{mg} / \mathrm{dL}$, palms and soles $>15 \mathrm{mg} / \mathrm{dL}$. The age of onset of jaundice gives a clue to possible aetiology. Appearance of jaundice in first 24 hours of birth is always pathological. Physiological jaundice is benign in nature and does not need any therapy. On the other hand, newborn with pathological jaundice always requires treatment.

The common causes of pathological jaundice are $\mathrm{ABO}$ incompatibilities, Rh incompatibilities, sepsis, G6PD deficiency and idiopathic. Jaundice in the newborn is a medical emergency, because unconjugated bilirubin is neurotoxic in certain concentration and under various conditions. A safe level of bilirubin is yet to be clearly defined. Thus, unconjugated hyperbilirubinemia may cause bilirubin encephalopathy or kernicterus.(3) 
Hence, early diagnosis and early interventions like phototherapy, exchange blood transfusion and treating the cause go a long way in proper management. The present study was conducted to know the aetiology of hyperbilirubinemia in neonates admitted in neonatal intensive care unit of Gauhati Medical College and Hospital, Guwahati, Assam.

\section{MATERIAL AND METHODS}

This observational study was conducted in Neonatal Intensive Care Unit, Gauhati Medical College and Hospital, over a period of 12 months (February 2015 to January 2016). A total number of 520 neonates with jaundice admitted in Neonatal Intensive Care Unit (NICU) were included in the study.

\section{Inclusion Criteria}

1. Neonates with jaundice delivered in the hospital and referred from peripheries, admitted in NICU during study period.

2. Neonates with serum bilirubin more than $10 \mathrm{mg} / \mathrm{dL}$.

\section{Exclusion Criteria}

1. Babies attending outpatient department only.

2. Babies who left, discharged against medical advice.

3. Parents who refused to sign the consent.

A written informed consent was taken from all parents and purpose of the study was explained to them. Parents were allowed to discontinue from the study at any time.

After taking the history in detail, clinical examination was performed with special reference to assessment of severity of jaundice and find out the cause of jaundice. We examined all the jaundiced newborn cases in natural day light in a white background. Jaundice was confirmed by estimation of serum bilirubin and its fraction. Blood groups Rh and ABO for both jaundiced newborn and mother were done. Other laboratory tests like direct Coombs test, G6PD screen, reticulocyte count, haematocrit etc. were done accordingly. If baby is unwell, sepsis screen and urine for reducing substances were ordered. Those well newborns which fit in definition of physiological jaundice were not investigated further. Additional laboratory investigations were done to find out the causes of neonatal hyperbilirubinemia as per the need.

\section{RESULTS AND OBSERVATIONS}

\begin{tabular}{|c|c|c|}
\hline Sex & Number of Cases & Percentage \\
\hline Male & 302 & $58.08 \%$ \\
\hline Female & 218 & $41.92 \%$ \\
\hline Total & $\mathbf{5 2 0}$ & $\mathbf{1 0 0} \%$ \\
\hline \multicolumn{2}{|c|}{ Table 1: Sex Wise Distribution of Neonate } \\
\hline
\end{tabular}

In this study, out of 520 jaundiced neonates 302 (58.08\%) were males and 218 (41.92\%) females.

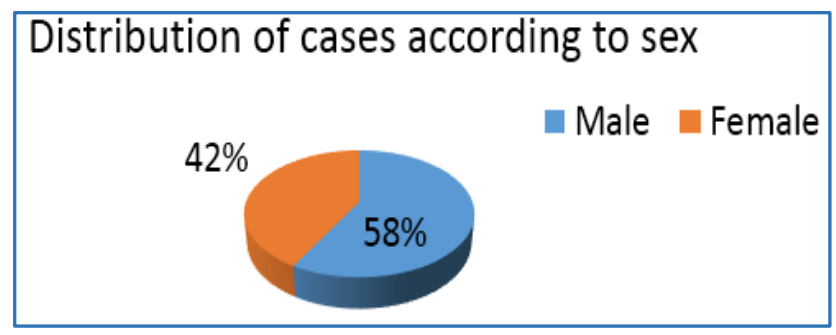

\begin{tabular}{|c|c|c|}
\hline Gestational Age & $\begin{array}{c}\text { Number of } \\
\text { Cases }\end{array}$ & Percentage \\
\hline More than 37 weeks (Term) & 251 & $48.26 \%$ \\
\hline $28-30$ weeks & 68 & $13.07 \%$ \\
\hline $31-32$ weeks & 109 & $20.96 \%$ \\
\hline $33-36$ weeks & 92 & $17.71 \%$ \\
\hline Total & $\mathbf{5 2 0}$ & $\mathbf{1 0 0} \%$ \\
\hline \multicolumn{2}{|c|}{ accorle 2: Distribution of Neonates } \\
\hline \multicolumn{2}{|c|}{} \\
\hline
\end{tabular}

In our study, out of total 520 neonates 251 (48.26\%) were term and $269(51.74 \%)$ were preterm neonates.

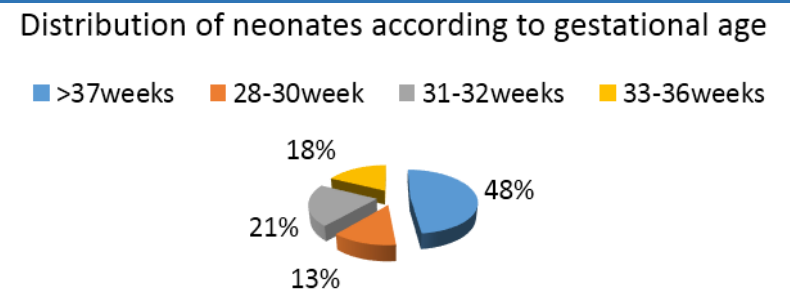

\begin{tabular}{|c|c|c|}
\hline Type of Jaundice & Number of Cases & Percentage \\
\hline Physiological & 224 & $43.07 \%$ \\
\hline Pathological & 296 & $56.93 \%$ \\
\hline Total & $\mathbf{5 2 0}$ & $\mathbf{1 0 0 \%}$ \\
\hline \multicolumn{2}{|c|}{$\begin{array}{c}\text { Table 3: Distribution of Jaundiced Neonate } \\
\text { according to Type of Jaundice }\end{array}$} \\
\hline
\end{tabular}

Table 3 shows that: Out of total 520 neonates, 224 (43.07\%) had physiological jaundice and 296 (56.93\%) had pathological jaundice.

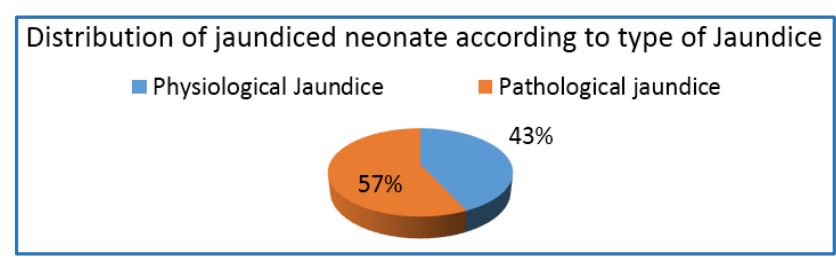

\begin{tabular}{|c|c|c|}
\hline Type of Jaundice & Number of Cases & Percentage \\
\hline Conjugated & 43 & $8.26 \%$ \\
\hline Unconjugated & 477 & $91.74 \%$ \\
\hline Total & 520 & $100 \%$ \\
\hline
\end{tabular}

Table 4 shows that: Out of total 520 neonates, 43 (8.26\%) had conjugated jaundice and 477 (91.74\%) had unconjugated jaundice.

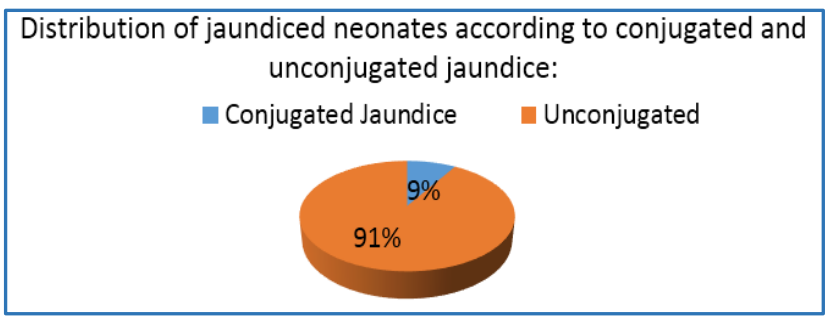




\begin{tabular}{|c|c|c|}
\hline Causes & $\begin{array}{c}\text { Number of } \\
\text { Cases }\end{array}$ & Percentage \\
\hline $\begin{array}{c}\text { Exaggerated } \\
\text { Physiological }\end{array}$ & 224 & $43.07 \%$ \\
\hline ABO incompatibility & 108 & $20.76 \%$ \\
\hline Rh incompatibility & 31 & $5.96 \%$ \\
\hline G6PD deficiency & 35 & $6.73 \%$ \\
\hline Sepsis & 36 & $6.92 \%$ \\
\hline Cephalhematoma & 15 & $2.88 \%$ \\
\hline Intrauterine infection & 7 & $1.34 \%$ \\
\hline Breast milk jaundice & 6 & $1.15 \%$ \\
\hline Hypothyroidism & 4 & $0.76 \%$ \\
\hline Idiopathic & 54 & $10.43 \%$ \\
\hline \multicolumn{2}{|c|}{$\begin{array}{c}\text { Table 5: Distribution of Neonates according } \\
\text { to Causes of Neonatal Hyperbilirubinemia }\end{array}$} \\
\hline
\end{tabular}

Table 5 shows that: Out of total 520 neonates, 224 (43.07\%) had exaggerated physiological jaundice, 108 (20.76\%) had ABO incompatibility, 31 (5.96\%) had $\mathrm{Rh}$ incompatibility, 35 (6.73\%) had G6PD deficiency, 36 (6.92\%) had sepsis, 15 (2.88\%) had cephalhematoma, 7 (1.34\%) had intrauterine infection, $6(1.15 \%)$ had breast milk jaundice, 4 $(0.76 \%)$ had hypothyroidism and $54(10.43 \%)$ were idiopathic jaundice.

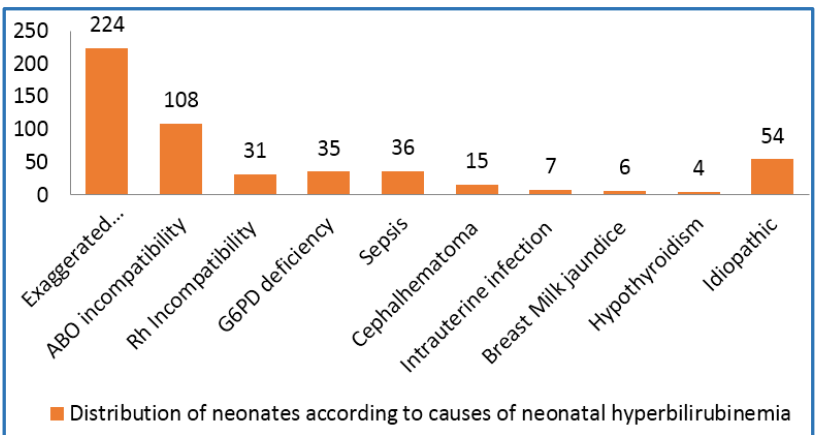

\section{DISCUSSION}

The study comprises of 520 newborns, in which 302 were males (58\%) and 218 were females (42\%). This is comparable to study done by Narang et al, 1996 India.(4) and Ahmad Ali et al.(5) It could be explained probably due to social bias, male being more cared for compared to female neonate. In our study, as per gestational age 269 (51.74\%) were preterm and 251 (48.26\%) were term babies.

Bhutani et al(6) and Ahmad Ali et al(5) in their studies found that prematurity was a significant risk factor for hyperbilirubinemia. Preterm newborns are more prone to develop jaundice due to immaturity of their bilirubin conjugating system, higher rate of haemolysis, increased enterohepatic circulation and decreased caloric intake.

In the present study, incidence of pathological jaundice $(55.76 \%)$ was more than physiological jaundice and is comparable to other studies like Singhal et al (1992) AIIMS $(n=454) .{ }^{(7)}$ and Garg Paridhi et al(8) in Maharashtra, India.

The present study reviews the causes responsible for neonatal jaundice. In number of cases, however, even the additional investigations fail to reveal any aetiological factors and these cases were then labelled as idiopathic.

In our study, it was observed that ABO incompatibility in 108 neonates (20.76\%) was comparable to Joshi et al 2004.(9) (28.8\%) and Ahmed Ali et al(5) (24.4\%). However, in another study conducted by Sgro $M$ et al(10) found that $A B O$ incompatibility (51.6\%), which was much higher than in our studies. In our study, Rh incompatibility was 5.96\% and G6PD deficiency was $6.73 \%$. All the cases having G6PD deficiency were male. We found $\mathrm{ABO}$ incompatibility was the most common cause followed by G6PD deficiency and $\mathrm{Rh}$ incompatibility among all haemolytic jaundiced neonate. The results are consistent with Sgro M et al.( 10) In our study, G6PD deficiency was found in 35 neonates constituting 6.73\%, which was much higher compared to Garg Paridhi et al(8), which was only 1 case $(0.9 \%)$. This may be due to different ethnic groups and tribes, which constitute the major population of Assam.

It is known that haemoglobinopathies are common among people of Assam. Hence, screening for G6PD deficiency and other haemoglobinopathies in neonatal jaundice may be adopted as a non-mandatory screening test in Assam, especially in case of severe neonatal hyperbilirubinemia without blood group incompatibility. Further, diagnosis of G6PD deficiency status also helps in prevention of future haemolysis due to exposure of offending drug. No aetiological factor for the jaundice could be established in 54 (10.43\%) babies and labelled as idiopathic jaundice. Various Indian studies have shown incidence of idiopathic jaundice to be ranging from $8.8 \%$ to $57 \%$, Verma $\mathrm{M}$ et al.(11)

\section{CONCLUSION}

We know that neonatal hyperbilirubinemia is a medical emergency, because unconjugated bilirubin is neurotoxic in certain concentration and under various conditions and may cause bilirubin encephalopathy or kernicterus. Paediatrician should take appropriate measure to bring down bilirubin level to a safe level. We should order additional laboratory tests to find out the treatable cause. Parents should be counselled to bring their babies early to hospital to prevent acute bilirubin encephalopathy and subsequent kernicterus. Close monitoring is required for G6PD deficient neonate in the first week of life, the period of increased risk. We should take necessary steps to prevent $\mathrm{Rh}$ incompatibility by providing appropriate antenatal care consisting of administration of Anti-D Immunoglobulin to unsensitised Rh negative mothers.

Screening for G6PD deficiency in neonatal jaundice may be adopted as a non-mandatory screening test in Assam, especially in case of severe neonatal hyperbilirubinemia without blood group incompatibility. In conclusion early detection of neonatal hyperbilirubinemia, proper monitoring, timely interventions and treating the underlying cause will reduce the morbidity and mortality among neonates. Thus, we can prevent mental retardation and cerebral palsy due to neonatal hyperbilirubinemia at the community level.

\section{REFERENCES}

1. Meharban Singh. Care of the New born, Sagar Publication, New Delhi-110001, 2004; 6 th edn:239-55.

2. Kramer LI. Advancement of dermal icterus in the jaundiced newborn. Am J Dis Child 1969;118(3):454-8.

3. Sharma JN. Manual of care of critical newborn, peepee publishers and distributors (p) ltd. 2007;1 $1^{\text {st }}$ edn:241-70.

4. Narang A, Ghatwala G, Kumar P, et al. Neonatal jaundice, an analysis of 551 cases. Indian paediatrics 1996;34:429-32.

5. Ahmad Ali, Anurag Tomar. Aetiological profile of neonatal hyperbilirubinemia in rural area of Rajasthan. IJB \& Medical research March 2015;4(2):223-32.

6. Bhutani VK. Evidence based issues regarding neonatal hyperbilirubinemia. Paediatrics review 2005;114:130-53. 
7. Singhal PK, Singh M, Paul VK, et al. Spectrum of neonatal hyperbilirubinemia: an analysis of 454 cases. Indian Paediatr 1992;29(3):319-25.

8. Garg Paridhi, Dayama Nilesh, Aggarwal Sumit, et al. Study of aetiology of neonatal jaundice at tertiary care centre in Maharastra. SJAMS ISSN 2320-6691, 2015;3(4c):1787-90.

9. Joshi BD, Singh R, Mahato D, et al. Clinico-laboratory profile of neonatal hyper-bilirubinemia in term babies at BP koirala institute of health science, dharan, Nepal. JNHRC 2004;2:30-2.
10. Sgro M, Campbell D, Shah V. Incidence and causes of severe neonatal hyperbilirubinemia in Canada. CMAJ 2006;175(6):587-90.

11. Verma M, Chhatwal J, Singh D. Neonatal hyperbilirubinaemia. Indian Journal of Paediatrics 1988;55(6):899-904. 